\title{
Arqueologia e potencial ecoturístico da Chácara Columbia em São Bernardo do Campo (SP)
}

\section{Archaeology and ecotourism potential of the Chácara Columbia in São Bernardo do Campo (SP, Brazil)}

\author{
Charles Bonetti
}

\section{RESUMO}

Diagnóstico prospectivo arqueológico realizado na Chácara Columbia, município de São Bernardo do Campo, São Paulo, em 2009. Relatório dos trabalhos entregue ao IPHAN-SP indica a existência de um sítio arqueológico com diferentes ocupações, possivelmente de diferentes épocas de povos ceramistas em função de dois tipos distintos de fragmentos cerâmicos encontrados. Há também a possibilidade desse sítio ter sido um local de passagem, talvez um sítio histórico, devido à existência de fragmentos de louça (?) ou porcelana (?), uma com as inscrições " $P$ Ir', "Rio de Janeiro" e o "Brasão do Império". Foi encontrado também um depósito de carapaças de conchas de moluscos, provavelmente de origem marinha, no interior de uma das quadras escavadas. O artigo apresenta proposta de criação de um museu de sítio para uso ecoturístico.

PALAVRAS-CHAVE: Arqueologia e Meio Ambiente; Museu de Sítio; Vestígios Cerâmicos e Malacológicos.

\section{ABSTRACT}

Prospective diagnosis archaeological carried out in Chácara Columbia, in São Bernardo do Campo city, São Paulo state, Brazil, in 2009. The work report delivered to the IPHAN (SP) indicates the existence of an archeological site with different occupations, possibly from different periods from people potters in function of two distinct types of ceramic fragments that were found. There is also the possibility of this place had been a place of passage, perhaps a historical site, due to the existence of fragments of ware (?) or porcelain (?), with the inscriptions "P II", "Rio de Janeiro" and the "Coat of the Brazilian empire". It was also found a deposit of shells of bivalve molluscs, probably from marine origin, in one of the quatrain excavated. This paper present one proposal for creation of a Museum of site for ecotouristic use.

KEYWORDS: Archaeology and Environment; Site Museum; Traces Ceramic and Malacological. 


\section{Introdução: um breve histórico}

A origem deste artigo encontra-se em um diagnóstico prospectivo arqueológico realizado na Chácara Columbia em $2009^{1}$, produzido a partir do intuito dos proprietários do imóvel ${ }^{2}$ em implantar empreendimento imobiliário condominial de uso residencial verticalizado ${ }^{3}$. Em função dos diversos impactos que tal empreendimento poderia provocar, o COMPAHC Conselho Municipal de Patrimônio Histórico e Cultural do município de São Bernardo do Campo, tombou provisoriamente a propriedade a fim de produzir um estudo multidisciplinar com o objetivo de identificar e qualificar a relevância e o caráter patrimonial da Chácara, bem como as consequências decorrentes de uma implantação imobiliária.

A primeira avaliação do COMPAHC deu-se através de um parecer elaborado pelo Grupo Técnico do Conselho, no qual recomendava, entre outras coisas, "um olhar mais sensível para com os atributos de valor do bem tombado, considerando o uso original e sua importância históricocultural"4 e acrescer ao estudo de intervenção um "parecer arqueológico, tendo em vista que se trata de área verde única ao longo da antiga ligação São Paulo-Santos"

\section{Caminhos do mar}

A área de pesquisa insere-se no contexto de um patrimônio cultural urbano, o que o reporta conceitualmente, de acordo com a recomendação da UNESCO - Organização das Nações Unidas para a Educação, à Ciência e à Cultura 6 , no âmbito dos "conjuntos históricos ou tradicionais", tais como sítios pré-históricos, cidades históricas, bairros urbanos antigos, aldeias e lugarejos.

Com este viés teórico-metodológico, a pesquisa arqueológica realizada na Chácara Columbia fez parte de um trabalho multidisciplinar de pesquisa, que também envolveu aspectos históricos, antropológicos e arquitetônicos. Sob tal perspectiva, o conceito de ambiência perpassou todo o trabalho, objetivando o entendimento, em caráter preliminar, do processo de ocupação local em um contexto urbano.

Quem hoje passa pela atual Avenida Senador Vergueiro, provavelmente ignora que esta possui um extenso processo de ocupação antrópica, por tratar-se de um dos caminhos que ligam o litoral ao antigo planalto de Piratininga, com relatos que remontam o séc. XVI. Tanto os cronistas, como a historiografia, demonstram que o processo histórico da Conquista valeu-se de antigas rotas indígenas (peabirus), cuja toponímia ainda identifica muitas vias na atualidade ${ }^{7}$.

A Chácara Columbia localiza-se em uma área que acompanha a antiga estrada do Caminho do Mar, cujas referências remontam a 1650, época em que Mem de Sá encarregou os jesuítas, capitaneados pelo Padre José de Anchieta, de abrirem novos caminhos ligando São Vicente ao Planalto Piratininga.

Descrições do séc. XVII mencionam o estabelecimento de sesmarias na região, notadamente a dos monges Beneditinos que aqui possuíram 
fazendas, onde hoje são os municípios de São Bernardo do Campo, Santo André e São Caetano do Sul. No início do século XVIII, é fundada a Capela da Boa Viagem por Antônio Pires Santiago à margem da Estrada do Mar, em torno da qual se formou o povoado de Nossa Senhora da Conceição de Boa Viagem. Em 23 de setembro de 1812 através da resolução régia, ocorre a constituição administrativa do município e, com o alvará do Marquês de Alegrete de 21 de outubro de 1812 São Bernardo é elevado à categoria de freguesia (Distrito). Contudo o desmembramento em relação a São Paulo data de 12 de março de 1889 e o município de São Bernardo é criado oficialmente apenas em 02 de maio de 1890, com sede no local da primitiva Vila de Santo André da Borda do Campo ${ }^{8}$.

Posteriormente, esse mesmo caminho serviu de base para a construção da estrada conhecida como a Antiga Estrada do Mar, uma construção que possuía mais de 70 pontes e que permitiu o tráfego de veículos. Em 1789, a estrada é recuperada e pavimentada com lajes de granito no trecho de Serra a mando do governador da Capitania Bernardo José de Lorena, passando a ser conhecida como Calçada de Lorena, importante patrimônio cultural material do município, que possui hoje trechos preservados, notadamente na porção serrana.

A primeira função desempenhada pelo espaço são bernardense, nos primórdios de sua ocupação, foi a de lugar de passagem, meio do caminho que ligava de um lado o litoral, porta de entrada do colonizador e, de outro, a Vila de São Paulo, capital da província. Sendo assim, as formas primitivas de ocupação deste espaço estavam ligadas impreterivelmente à instalação dos primeiros caminhos, trilhas e estradas ligando estes dois extremos (COMPAHC, $\mathrm{s} / \mathrm{d})$.

Em 1837, é construída a Estrada da Maioridade, utilizando parte do traçado da Estrada do Mar que entre 1862 e 1864, foi reformada por José Vergueiro, para o alargamento da via e criação de um novo traçado no trecho que cortava o Planalto, do Ponto Alto em São Bernardo até São Paulo.

Com a inauguração da estrada de ferro em 1867, iniciase o processo de degradação do antigo caminho, causando sua inutilização até a década de 1910. A partir deste momento, a ferrovia começa a ser recuperada, principalmente quando Rudge Ramos, em 1920, cria a Sociedade Caminho do Mar, responsável pela reconstrução da estrada, estabelecendo a cobrança de um pedágio que durou até 1923, ano em que quando o Governo do Estado a adquiriu e abriu-a ao público. Atualmente, o Caminho do Mar ou Estrada Velha do Mar, como é conhecida, está com trechos fechados à visitação pública e ao tráfego, apesar da intensa frequência turística e escolar, pois serve de acesso aos testemunhos das antigas ocupações históricas COMPAHC, s/d). 
Apesar de sua importância histórica como área de transição entre o Planalto e a Baixada Santista, o município de São Bernardo do Campo é tradicionalmente lembrado apenas como um local de passagem e não de ocupação, impressão causada em boa parte pela ausência de construções coloniais de grande monta. Essa mentalidade cultural-histórica é refletida no nome da avenida paralela à chácara Colúmbia, Caminho do Mar, um traço cultural indicador de certa impermanência - própria aos paulistas de uma forma geral $^{9}$-, uma das prováveis explicações para o não conhecimento do local exato da fundação do Município. Analogia semelhante pode também ser aplicada para o município de São Paulo, onde o exato local de fundação da cidade ainda gera controvérsias entre os pesquisadores.

\begin{abstract}
Alguns mapas e textos do século XVII apresentam-nos a vila de São Paulo como centro de amplo sistema de estradas expandindo-se rumo ao sertão e à costa. Os toscos desenhos e os nomes estropiados desorientam, não raro, quem pretenda servir-se desses documentos para a elucidação de algum ponto obscuro de nossa geografia histórica. Recordam-nos, entretanto, a singular importância dessas estradas para a região de Piratininga, cujos destinos aparecem assim representados como em um panorama simbólico (HOLANDA, 2008, p.19).
\end{abstract}

Inserida em um primitivo vale, com a presença de rios muito próximos como o Córrego dos Meninos e o Riberão dos Couros, e ao lado de um antigo peabiru de intenso fluxo em direção à Baixada Santista, o local da pesquisa abrigou, muito possivelmente, os habitantes originais da região, bem como o pousio de antigos tropeiros, comerciantes e viajantes que dessa rota utilizaram-se. Diante disso e, ainda, tendo em vista que uma das atribuições da Arqueologia é a reconstrução da paisagem cultural, principalmente a de antes do início do processo de urbanização, podemos considerar a atual Chácara Columbia como uma importante área de pesquisa, local de estabelecimento de antigas ocupações humanas e uma das poucas áreas verdes remanescentes no bairro de Rudge Ramos (Figura 1).

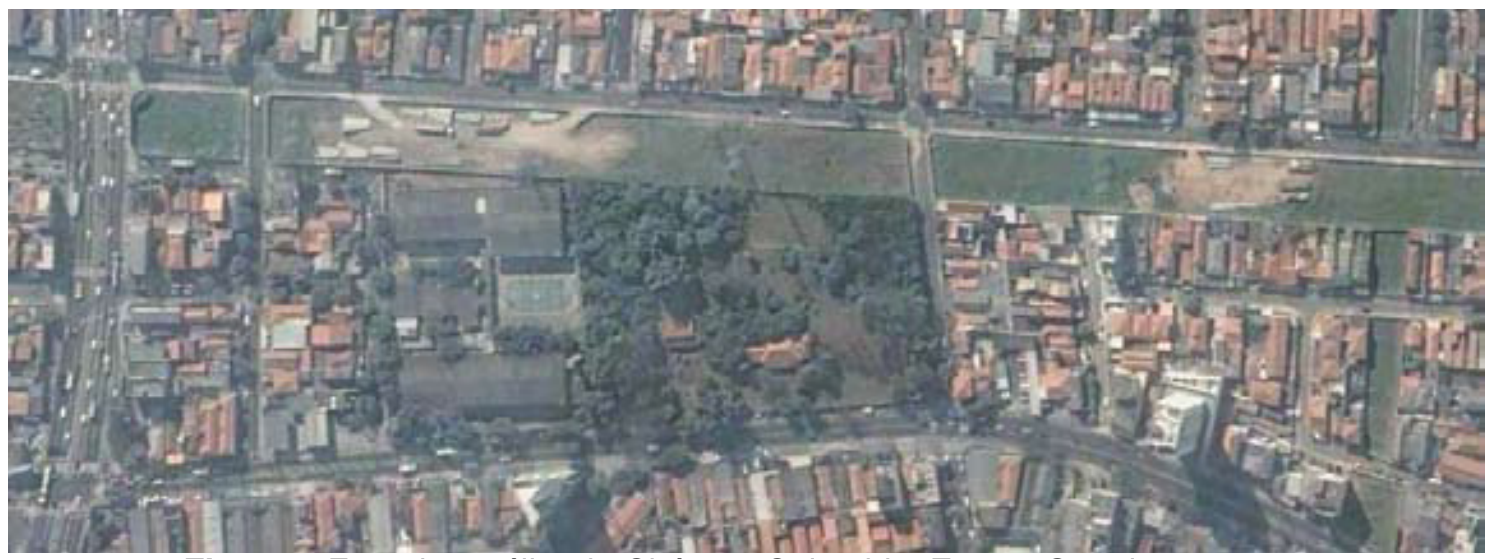

Figura1: Foto de satélite da Chácara Columbia. Fonte: Google maps.

Figure 1: Satellite photo of the Chácara Columbia. Source: Google maps. 
Os vestígios arqueológicos encontrados no interior da Chácara Columbia podem colaborar para a composição de um quadro mais completo do processo de ocupação, não apenas do município de São Bernardo do Campo, mas também do Planalto Paulista. Ressaltamos que este artigo é o único trabalho de natureza arqueológica realizado no local de pesquisa, portanto as informações aqui apresentadas são de caráter pontual, mas podem servir de referência para trabalhos arqueológicos futuros na região.

\section{A área de pesquisa e o diagnóstico prospectivo}

A Chácara Columbia possui uma área de 14.534,85 metros quadrados, ladeada por uma escola municipal a noroeste, pela linha de alta tensão a nordeste, pela Rua Sapucaí a sudeste e pela Avenida Senador Vergueiro a sudoeste. Existem em seu interior restos de cinco edificações do período moderno de urbanização: uma residência principal para uso, provável, de veraneio; uma casa secundária, aparentemente do caseiro e demais empregados; uma área de lazer com um galpão, um vestiário e um pergolado; além de uma piscina tomada pela vegetação. Há também uma área extensa com árvores nativas e exóticas, ocupando a Chácara Colúmbia quase a totalidade de um quarteirão.

Os trabalhos de escavação tiveram por objetivo realizar um diagnóstico prospectivo arqueológico, a fim de verificar a existência de vestígios e deixando claro que, em se encontrando material arqueológico, as prospecções cessariam, pois se tinha o intuito de realizar um mapeamento inicial do local para a orientação de trabalhos futuros. A retirada de amostras visou uma caracterização cultural inicial e a identificação tipológica do(s) sítio(s) arqueológico(s) ${ }^{10}$.

Após vistoria inicial, verificou-se a não existência de material arqueológico de superfície. Por ser uma área de pesquisa que sofreu intensa intervenção antrópica urbana, acreditávamos serem mínimas as possibilidades de existência de vestígios antigos. Em função do tamanho da área de pesquisa, resolvemos mapeá-la criando pontos de intersecção artificiais através de uma malha de 20 por $20 \mathrm{~m}$, obtendo assim 28 pontos para a escavação de quadras de $1 \mathrm{~m}^{2}$. As sondagens foram realizadas com profundidade variada, em função da especificidade de cada ponto, inicialmente estipulada em torno de $1 \mathrm{~m}$, superando a camada estratigráfica de entulho e de aterro, em busca do solo original e de uma possível ocupação humana antiga.

No total foram realizadas 27 prospecções dos 28 pontos originais estabelecidos, seguindo a orientação de quatro troncos principais paralelos à Av. Senador Vergueiro A,B, C, e D, cada qual com sete pontos numerados, originando assim a nomenclatura das sondagens, do PA1 ao PD7 (Figura 2). 


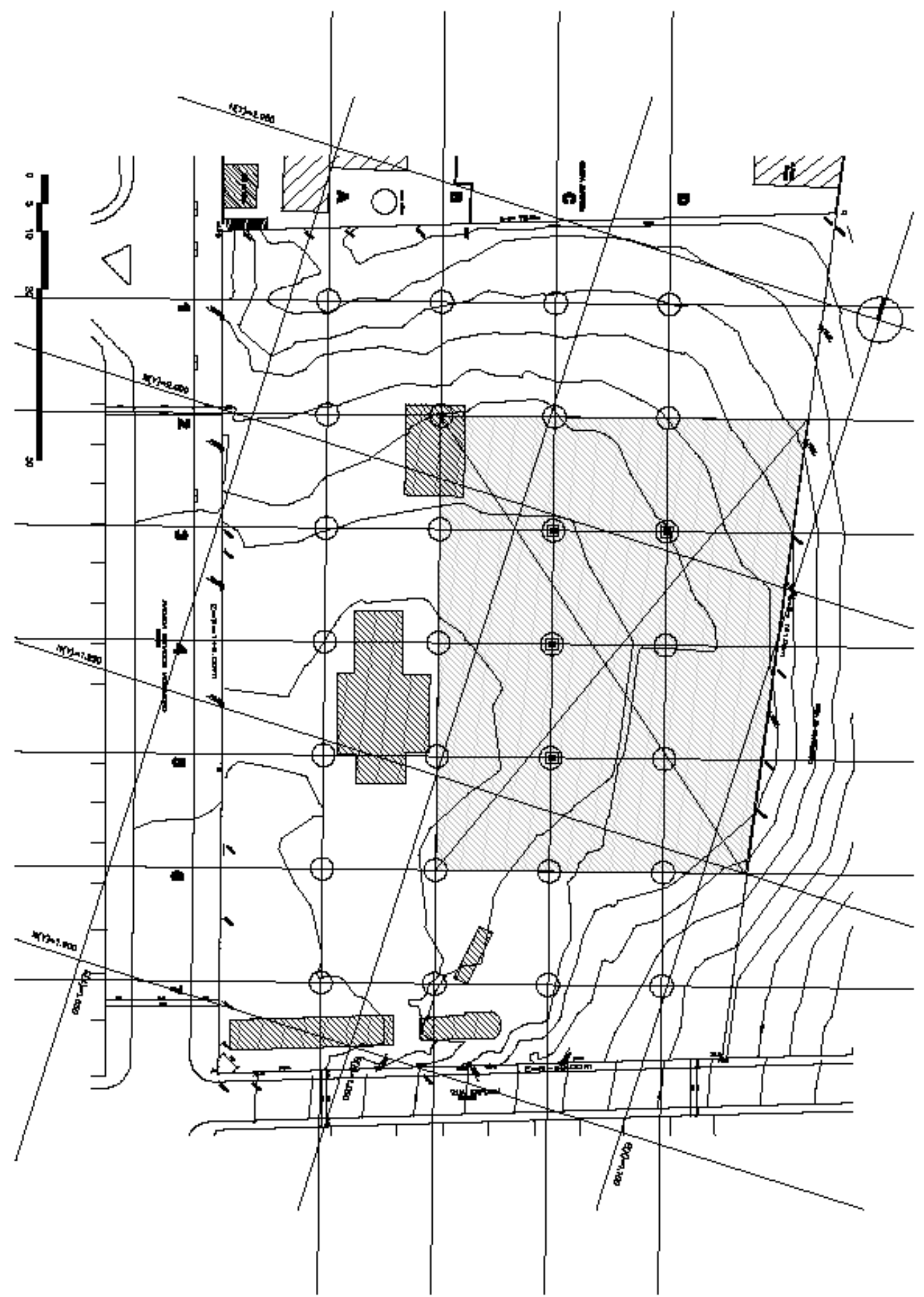

Figura 2: Planta da área pesquisada com a indicação das estruturas arquitetônicas, da malha original de 20 por $20 \mathrm{~m}$ com os 28 pontos de sondagens. A área em destaque corresponde a de interesse arqueológico sendo os quatro pontos em seu interior os locais onde encontrou-se vestígios arqueológicos. Fonte: Instituto Peabiru, a partir de registros dos trabalhos arqueológicos de Charles Bonetti.

Figure 2: Floor plan searched indicating the architectural structures, the original mesh 20 by $20 \mathrm{~m}$ with 28 points polls. The highlighted area is the archaeological interest are the four points inside the places where it was found archaeological remains. Source: Instituto Peabiru, from records of archaeological works of Charles Bonetti. 
Durante as escavações, superada a camada de superfície com a capa vegetal e de entulho, encontramos basicamente dois tipos de solo: um de coloração marrom escura, mais próximo da superfície, e outro de coloração marrom amarelada, camada estratigráfica na qual os vestígios arqueológicos estavam depositados. Em quatro dos pontos (PC3, PC4, PC5 e PD3), encontrou-se material arqueológico, que foi coletado para análise e classificação tipológica preliminar. A seguir a descrição dos trabalhos realizados nos pontos onde isso de deu. Ressaltamos que apenas uma ampla pesquisa arqueológica pode revelar se as evidências indicam a existência de um, dois ou até três sítios no local.

Sondagem PC3 (Figuras 3, 4, 5, 6, 7 e 8):

Superfície: Na superfície da quadra havia lixo queimado, com restos de pastas de fichário, grampos e material não identificado.

0-15cm: retirada da capa vegetal, areia e terra misturados;

0-25cm: entulho e resto de fichários queimados;

0-30cm: sem vestígios; início da terra marrom amarelada.

30-40cm: material arqueológico: borda cerâmica encontrada no canto superior esquerdo da quadra (perfil da Av, Sen. Vergueiro). Fragmento de borda com incisões verticais, cerâmica ungulada (?) e com sinais de queima.

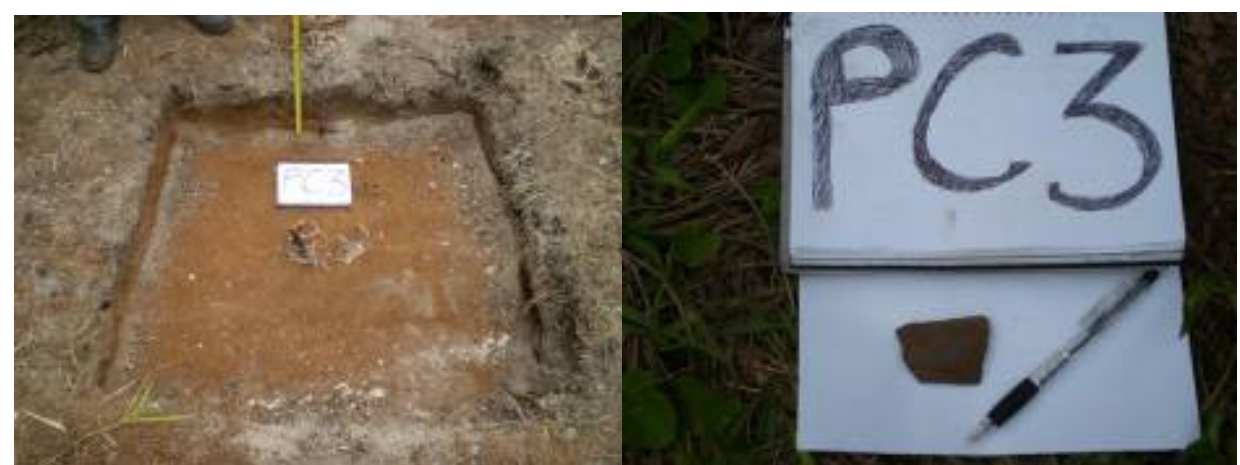

Figura 3: PC3. Quadra com a retirada da capa vegetal e os restos de fichário de pastas de arquivo queimados. Em detalhe, o fragmento de borda. Fotos: Charles Bonetti.

Figure 3: PC3. Court with the removal of vegetation cover and the binder remains of burned file folders. In detail, the edge fragment. Photo: Charles Bonetti.

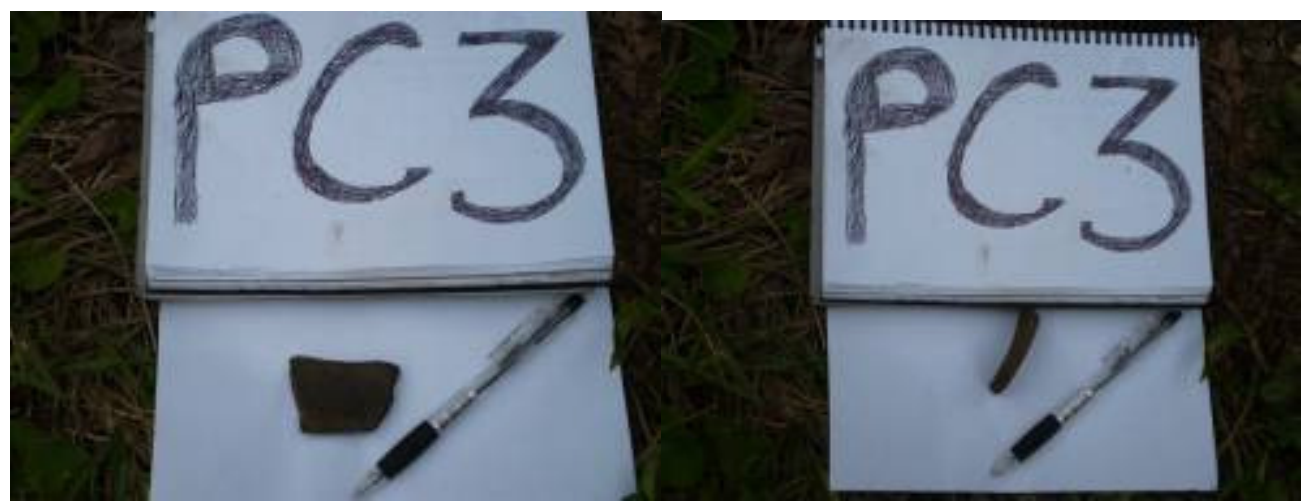

Figura 4: Detalhes da face interna e do perfil do fragmento de borda cerâmica.

Fotos: Charles Bonetti.

Figure 4: Inner face of the details and the ceramic edge fragment profile.

Photos: Charles Bonetti. 


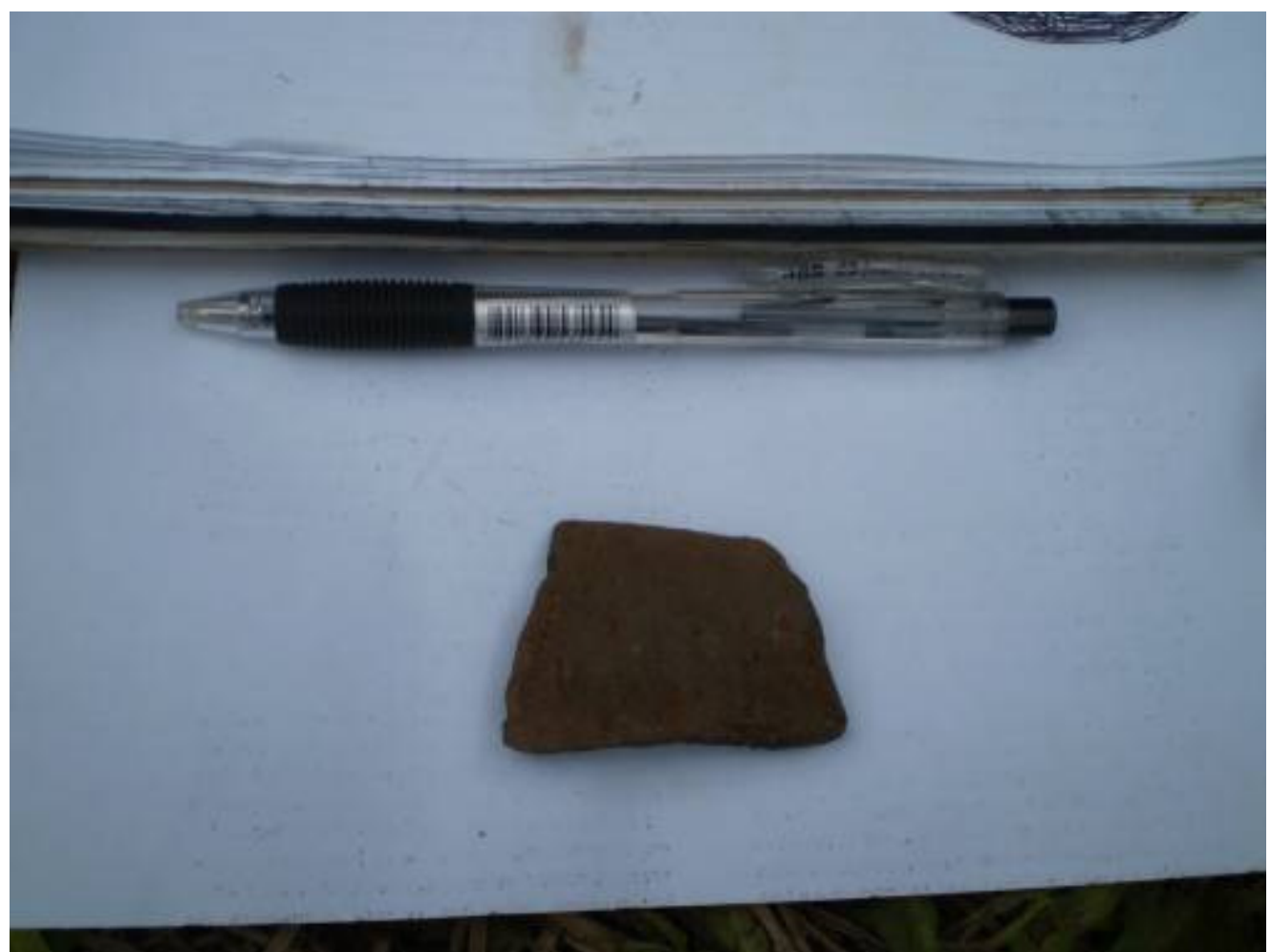

Figura 5: Detalhe da face externa do fragmento de borda cerâmica. Foto: Charles Bonetti. Figure 5: Detail of the outside surface of the ceramic edge fragment. Photo: Charles Bonetti.

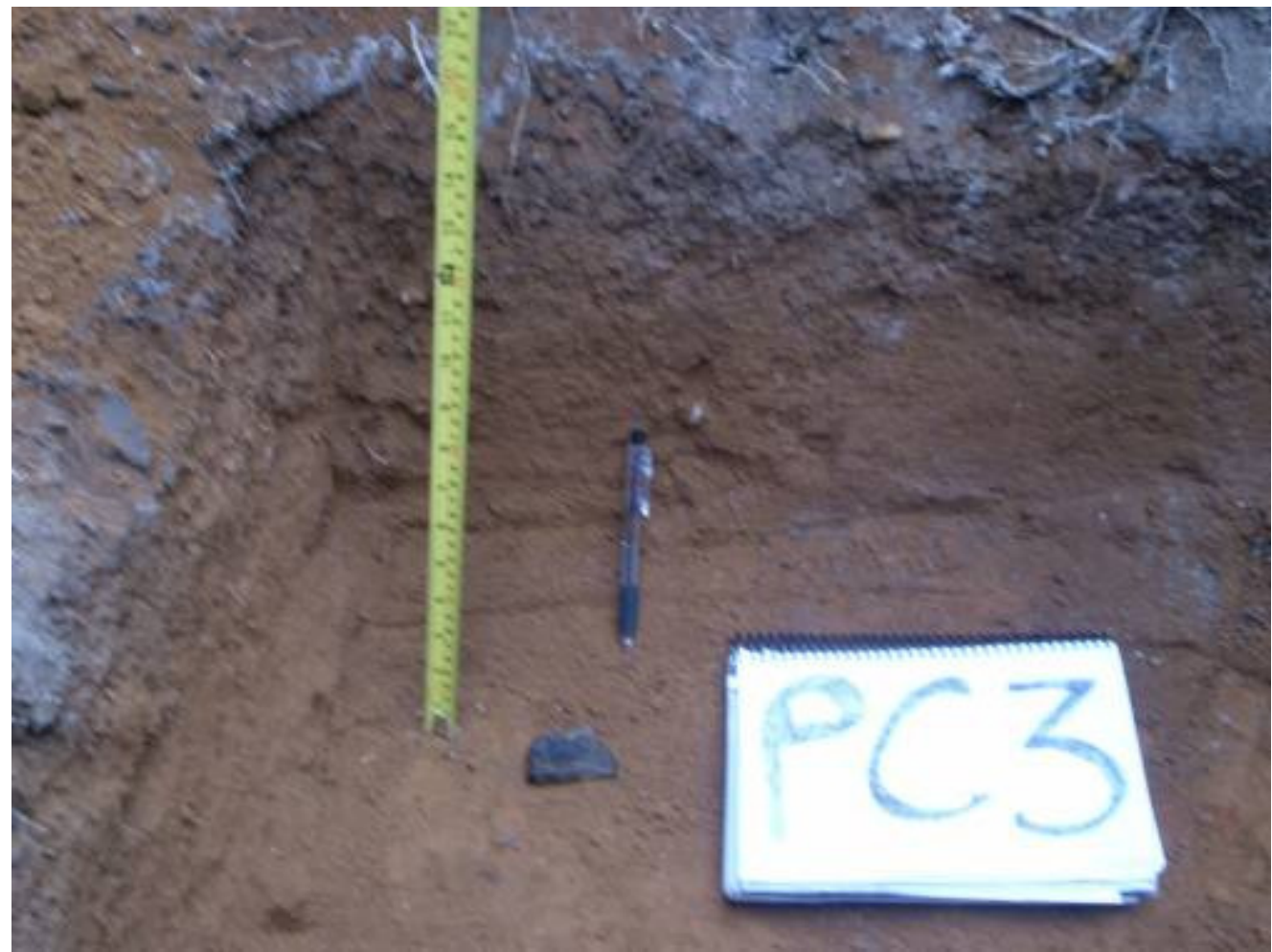

Figura 6: Local onde o fragmento de borda foi encontrado a $40 \mathrm{~cm}$ de profundidade.

Foto: Charles Bonetti.

Figure 6: Location where the edge fragment was found $40 \mathrm{~cm}$ deep.

Photo: Charles Bonetti. 


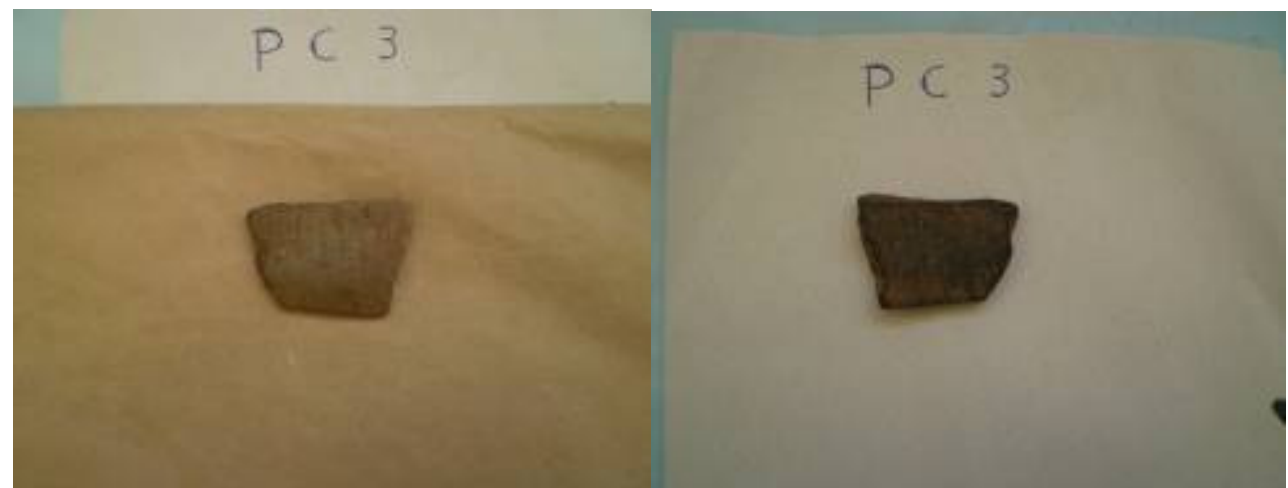

Figura 7: Detalhe da face externa e interna da borda com os detalhes de incisões e com sinais de queima. Fotos: Charles Bonetti.

Figure 7: Detail of the outer and inner edge with the details of incisions and burning signals. Photos: Charles Bonetti.

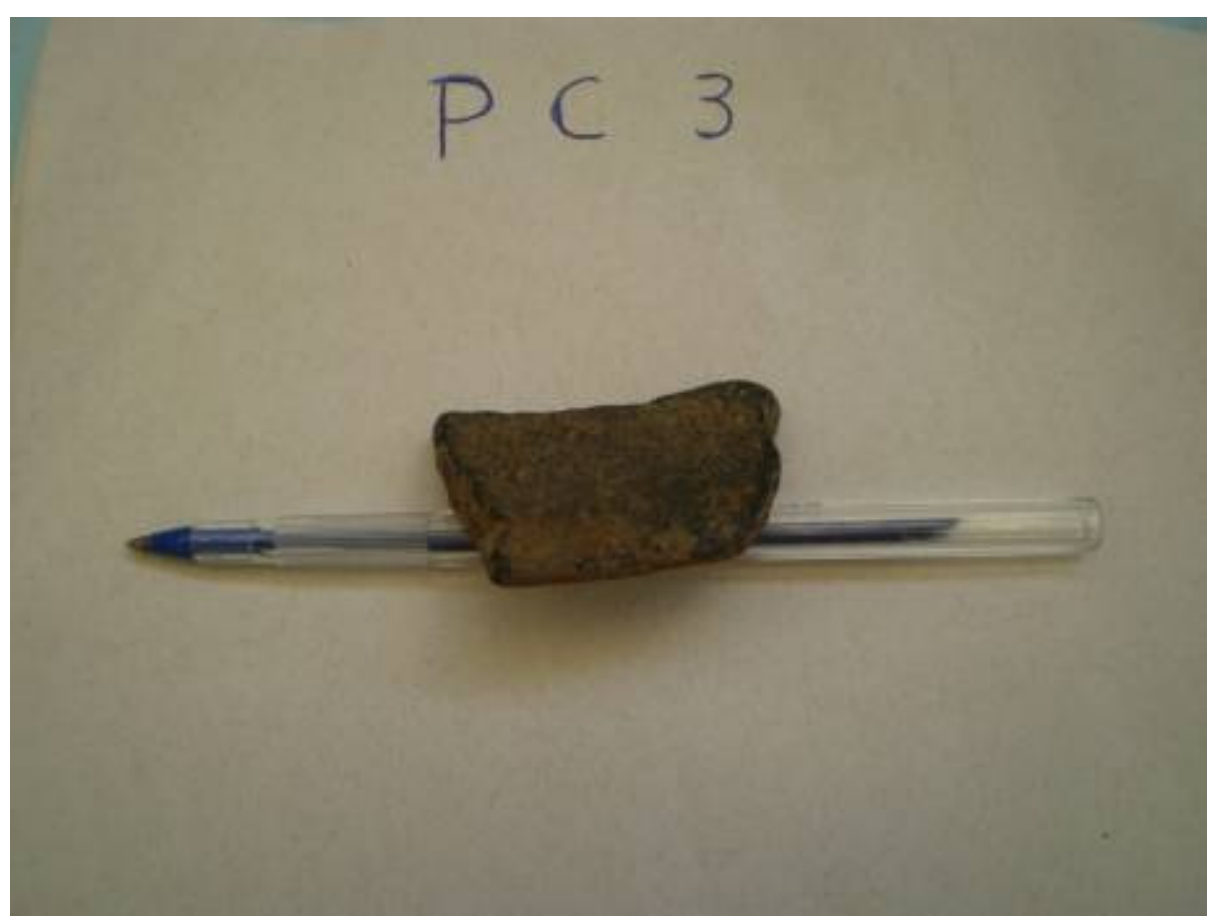

Figura 8: Detalhe do fragmento de borda na posição vertical. Foto: Charles Bonetti. Figure 8: Edge detail fragment upright. Photo: Charles Bonetti.

Esse fragmento de borda possui incisões horizontais e sinais de queima. Por se tratar de uma borda, será possível a determinação de seu diâmetro original em laboratório. As escavações encerraram-se na profundidade de $40 \mathrm{~cm}$, seguindo a proposta teórico-metodológica do trabalho.

Sondagem PC4 (Figuras 9, 10, 11 e 12):

Superfície: sem evidência de material.

$0-10 \mathrm{~cm}$ : retirada de camada vegetal;

20-30cm: fragmentos de carvão a $30 \mathrm{~cm}$ de profundidade (diâmetro entre 2 e $3 \mathrm{~mm})$ : material contaminado, pois está no sedimento que contém entulho; 
30-40cm: a $35 \mathrm{~cm}$, encontramos fragmento de vidro de $4 \mathrm{~mm}$ de espessura. A $40 \mathrm{~cm}$ de profundidade, encontramos fragmentos cerâmicos corrugados com sinais de queima. No perfil da quadra da face da escola, há um fragmento ou parte de um vaso cerâmico (?) ou urna (?) que está evidenciado. O objeto cerâmico ainda está enterrado nesse local e foi evidenciado no processo de decapagem.

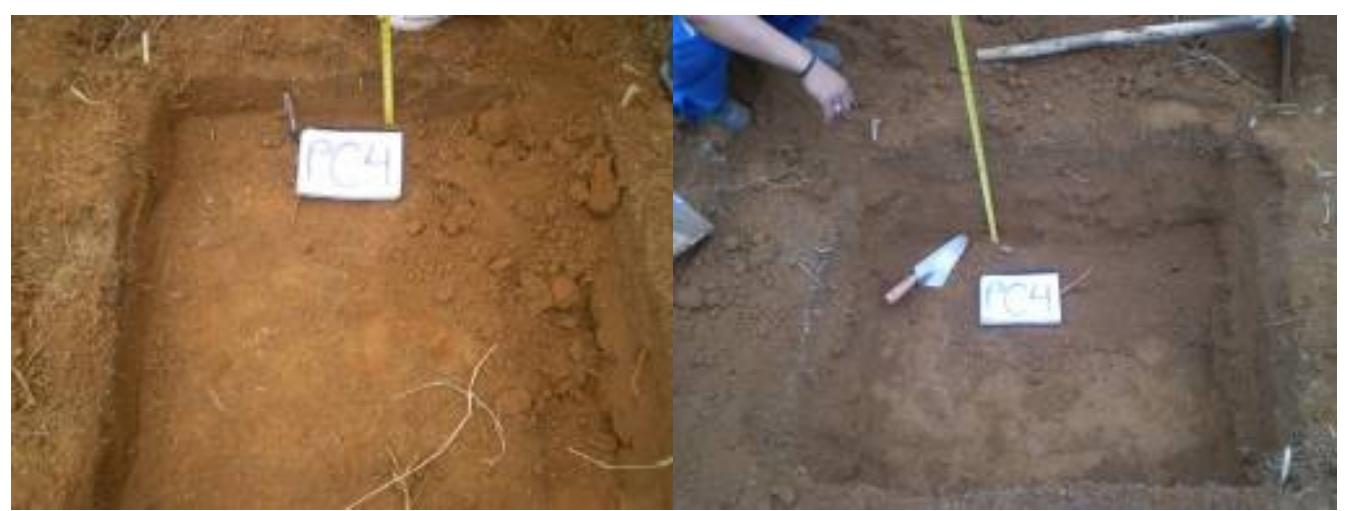

Figura 9: Escavação da quadra PC4 a 20cm de profundidade e imagem do local (perfil da escola) com os fragmentos cerâmicos. Fotos: Charles Bonetti.

Figure 9: block Dig PC4 $20 \mathrm{~cm}$ depth and location of the image (the school profile) with ceramic fragments. Photos: Charles Bonetti.

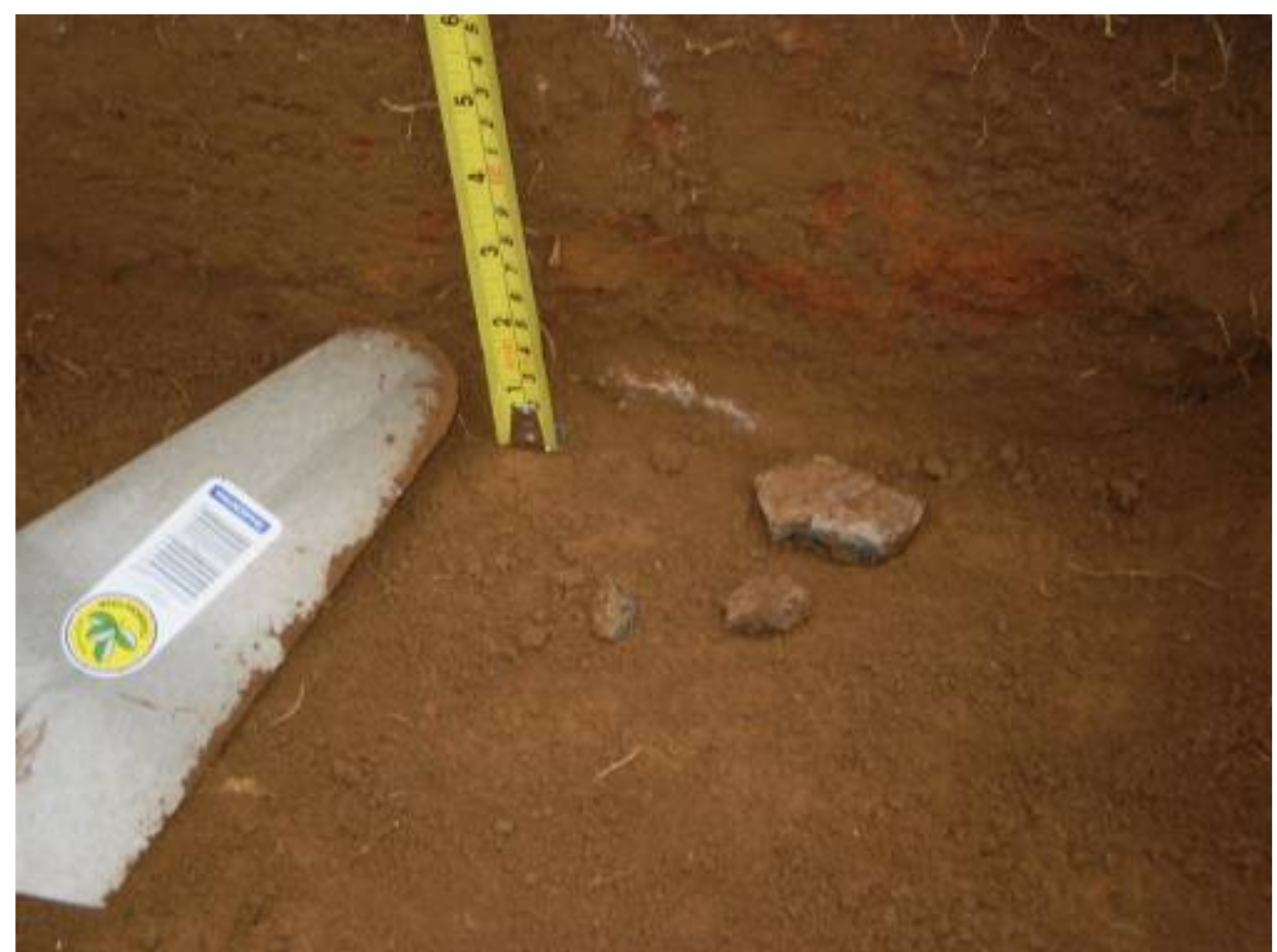

Figura 10: Detalhe dos três fragmentos que se desprenderam do vaso cerâmico (?) ou urna (?) evidenciado no perfil (escola). Foto: Charles Bonetti.

Figure 10: Detail of the three pieces that have broken off from the ceramic vase (?) or urn (?) shown in the profile (school). Photo: Charles Bonetti. 


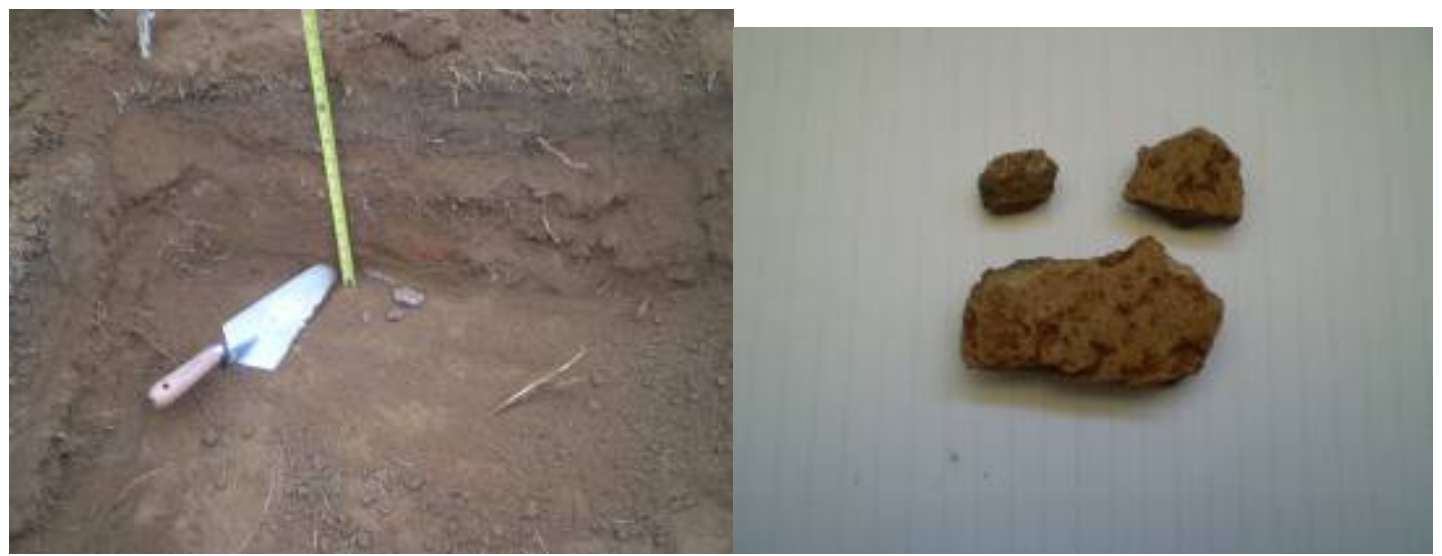

Figura 11: Detalhe dos três fragmentos que se desprenderam do vaso cerâmico (?) ou urna (?) evidenciado no perfil e da face externa dos três fragmentos. Fotos: Charles Bonetti.

Figure 11: Detail of the three pieces that have broken off from the ceramic vase (?) or urn (?) shown in profile and the outer face of the three fragments. Photos: Charles Bonetti.

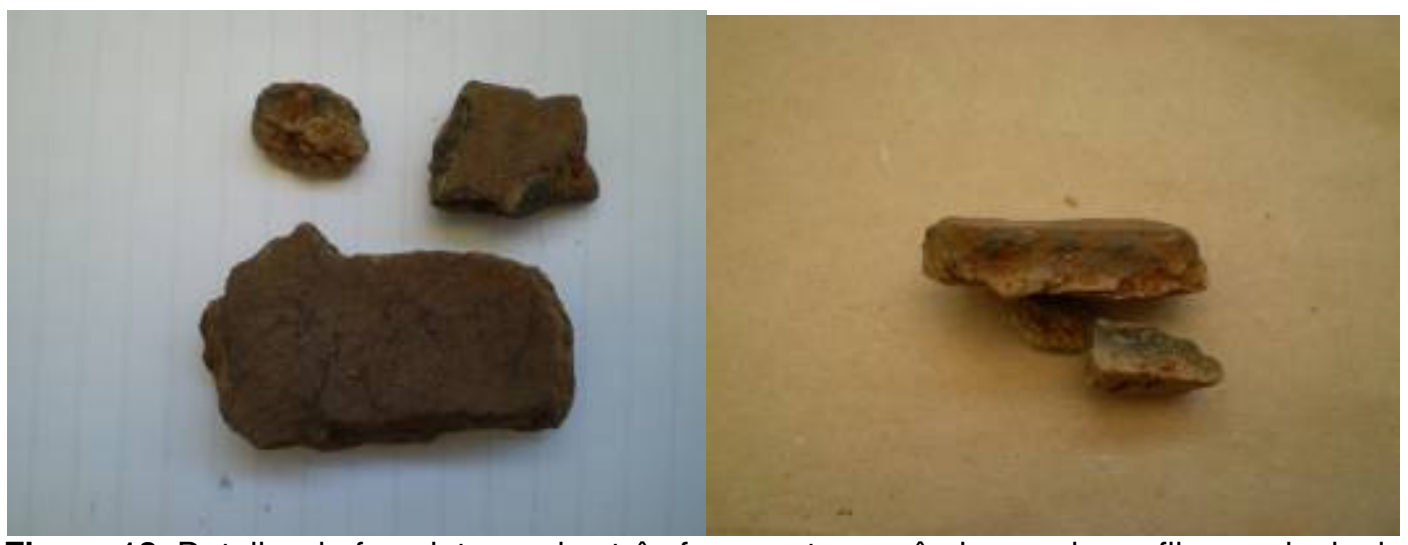

Figura 12: Detalhe da face interna dos três fragmentos cerâmicos e do perfil com sinais de queima. Fotos: Charles Bonetti.

Figure 12: Detail of the inner face of the three ceramic fragments and firing profile with signals. Photos: Charles Bonetti.

Apesar da proximidade da sondagem anterior, o tipo dos fragmentos cerâmicos encontrados nessa sondagem é diferente, o que leva a crer na existência de dois sítios cerâmicos distintos, ou de um sítio cerâmico com dois tipos de ocupação.

\section{Sondagem PC5 (Figura 13):}

Superfície: sem evidência de material;

0-10cm: retirada da capa vegetal e entulho: carvão; fragmento de vidro verde;

10-20cm: fragmentos de louças (?) ou porcelanas (?) cromadas;

20-30cm: restos de carvão;

40-50cm: restos de carvão;

Essa sondagem apresentou uma quantidade maior de carvão e de fragmentos de louça (?) ou porcelana (?) pintadas. 


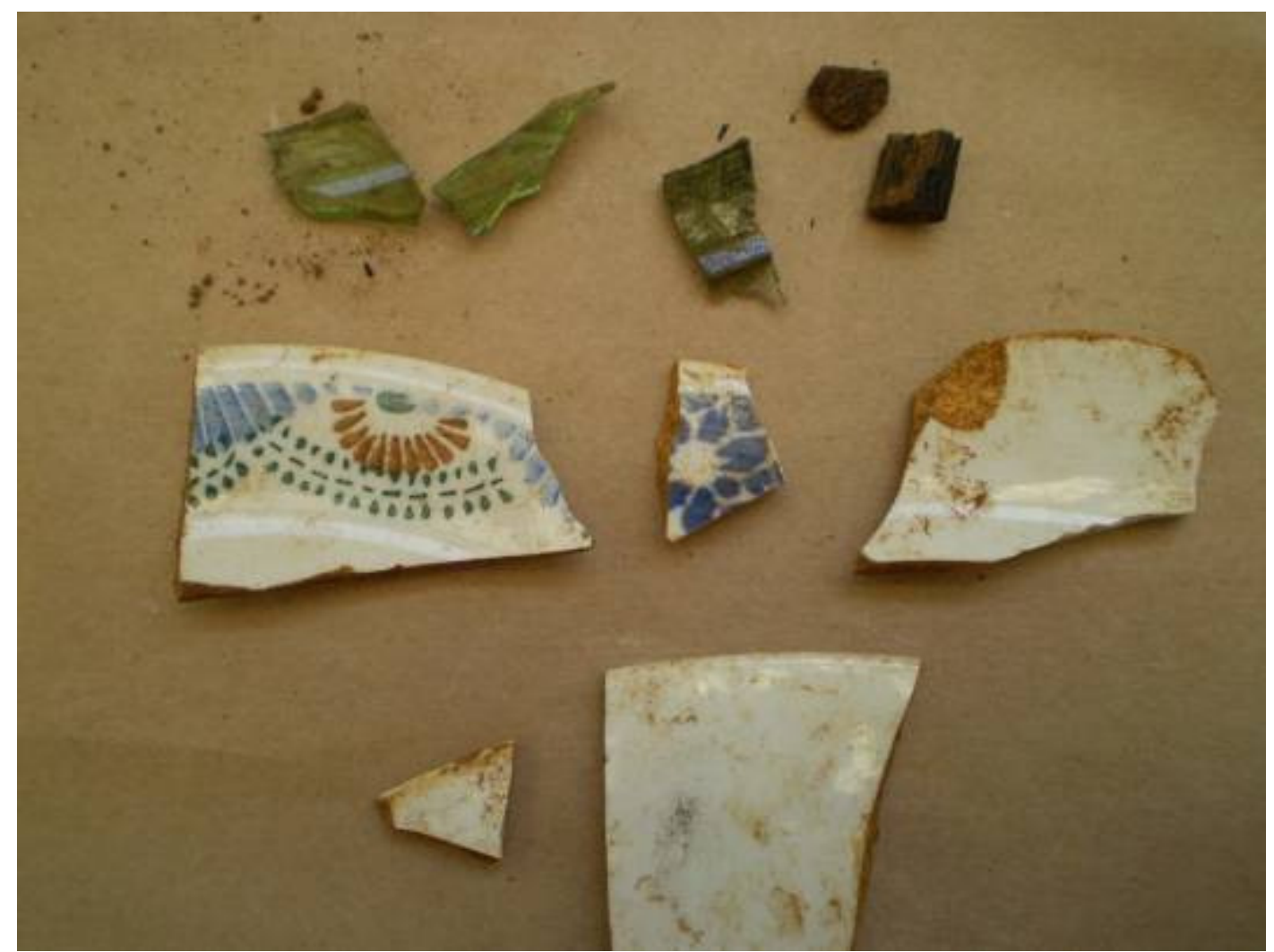

Figura 13: Detalhe dos fragmentos de louça ou porcelana pintada, fragmentos de vidro e carvão. Fotos: Charles Bonetti.

Figure 13: Detail of painted china or porcelain pieces, glass fragments and coal.

Photos: Charles Bonetti.

Sondagem PD3 (Figuras 14, 15, 16, 17, 18 e 19):

Superfície: sem evidência de material;

0-10cm: retirada da capa vegetal. Terra marrom escura, clareando conforme o aumento da profundidade escavada;

10-20cm: fragmento de porcelana branca(?) ou louça (?) com desenhos e uma especial com as inscrições "PIl" e "Rio de Janeiro";

20-30cm: terra marrom clara com fragmento de vidro e restos de plástico;

30-40cm: pacote de conchas marinhas bivalves e fragmentos de ossos de ave (?). Canto superior esquerdo da quadra do perfil da escola. A análise preliminar da espécie de bivalve encontrado indicou ser da espécie Eurhomalia lenticularis (SOMERBY, 1835) ou Eurhomalia rufa (LAMARCK, 1818). 


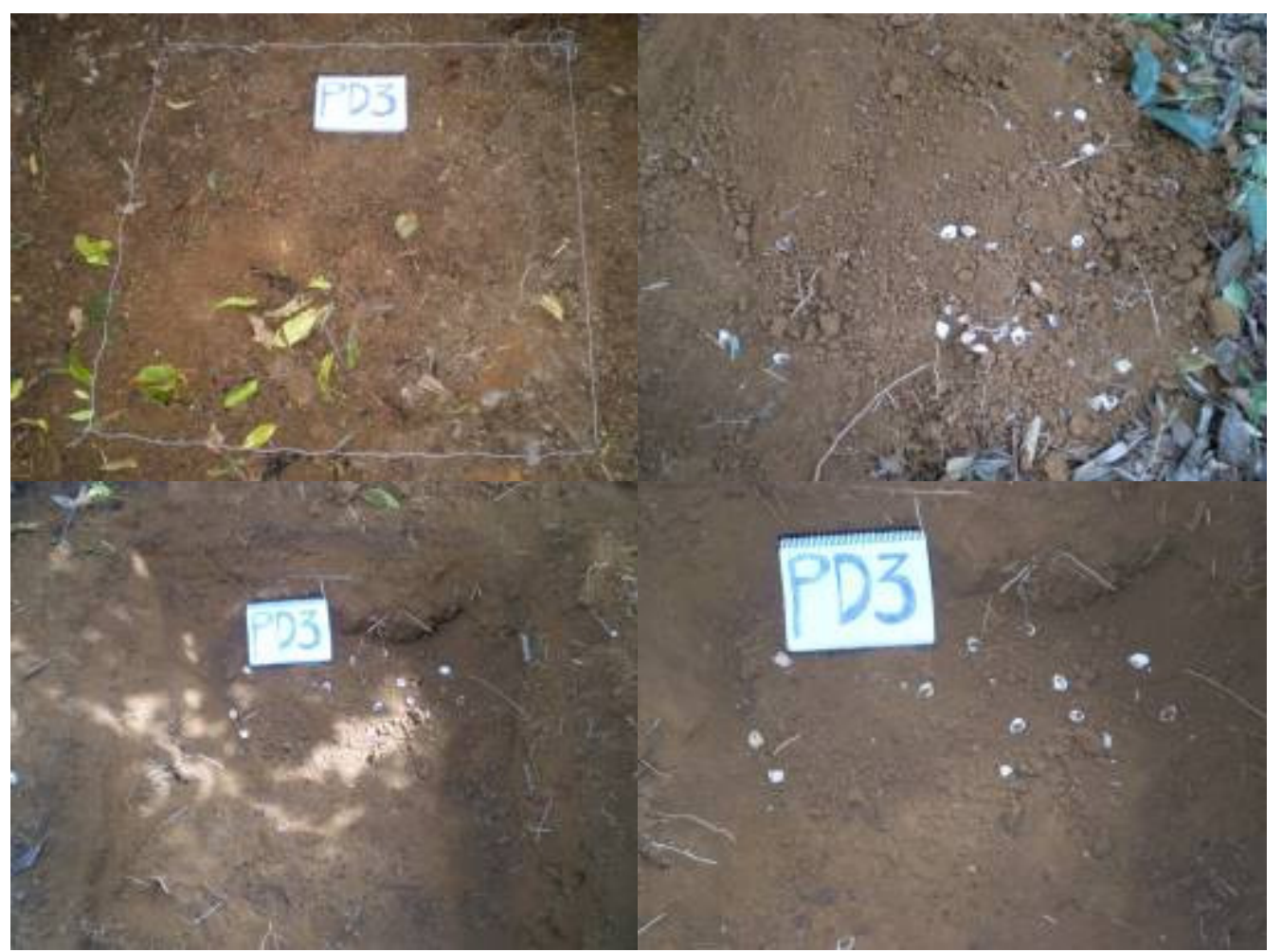

Figura 14: Escavação de PD3 com detalhe do depósito de conchas. Fotos: Charles Bonetti. Figure 14: PD3 Excavation in detail the deposits shells. Photos: Charles Bonetti.

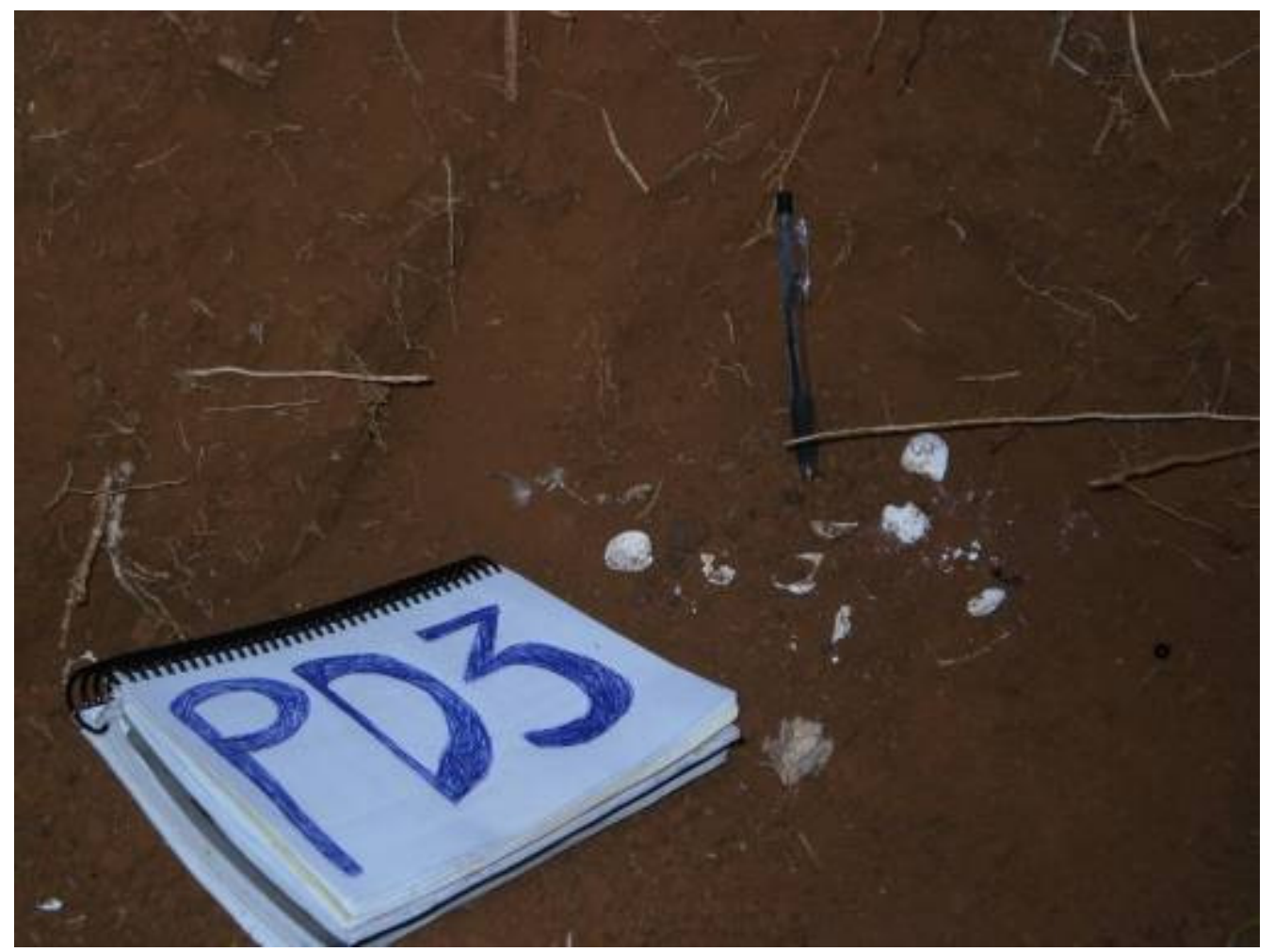

Figura 15: Detalhe do depósito de conchas no canto esquerdo superior da quadra. Fotos: Charles Bonetti.

Figure 15: Shells deposit detail in the upper left corner of the court. Photos: Charles Bonetti. 


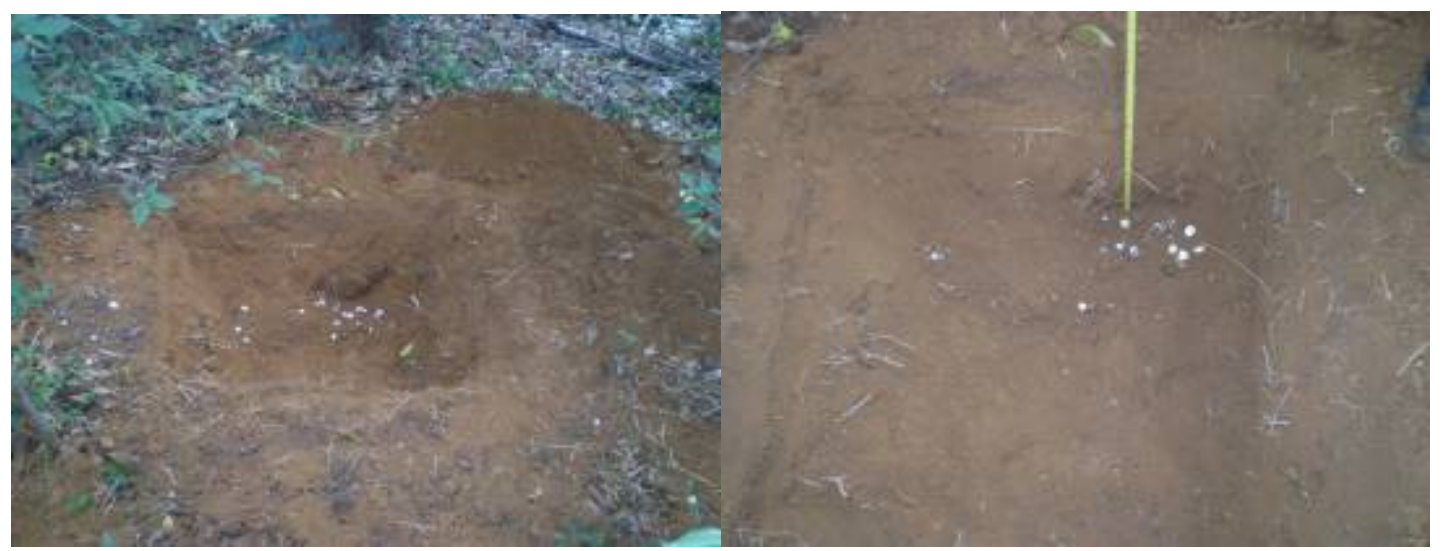

Figura 16: Escavação de PD3 com detalhe do depósito de conchas. Fotos: Charles Bonetti. Figure 16: PD3 Excavation in detail the deposit shells. Photos: Charles Bonetti.

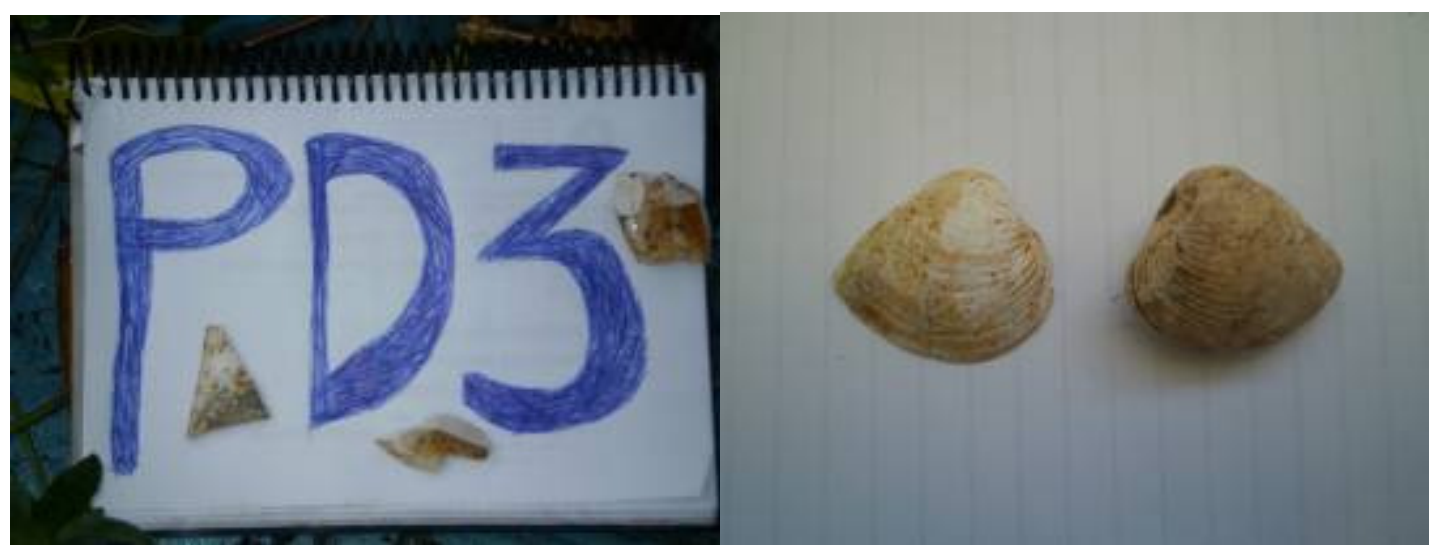

Figura 17: Fragmentos de louça ou porcelana com desenho encontrados durante as escavações, entre os quais encontrou-se a inscrição "PII" em um dos fragmentos. Detalhe do tipo de bivalve encontrado. Note a existência de bivalves inteiros, o que pode indicar a base do sítio conchífero. Fotos: Charles Bonetti.

Figure 17: Fragments or porcelain dish with drawing found during the excavations, including met the inscription "PII" in one of the fragments. Detail the type of bivalve found. Note the existence of whole bivalves, which can indicate the base conchífero site.

Photos: Charles Bonetti.

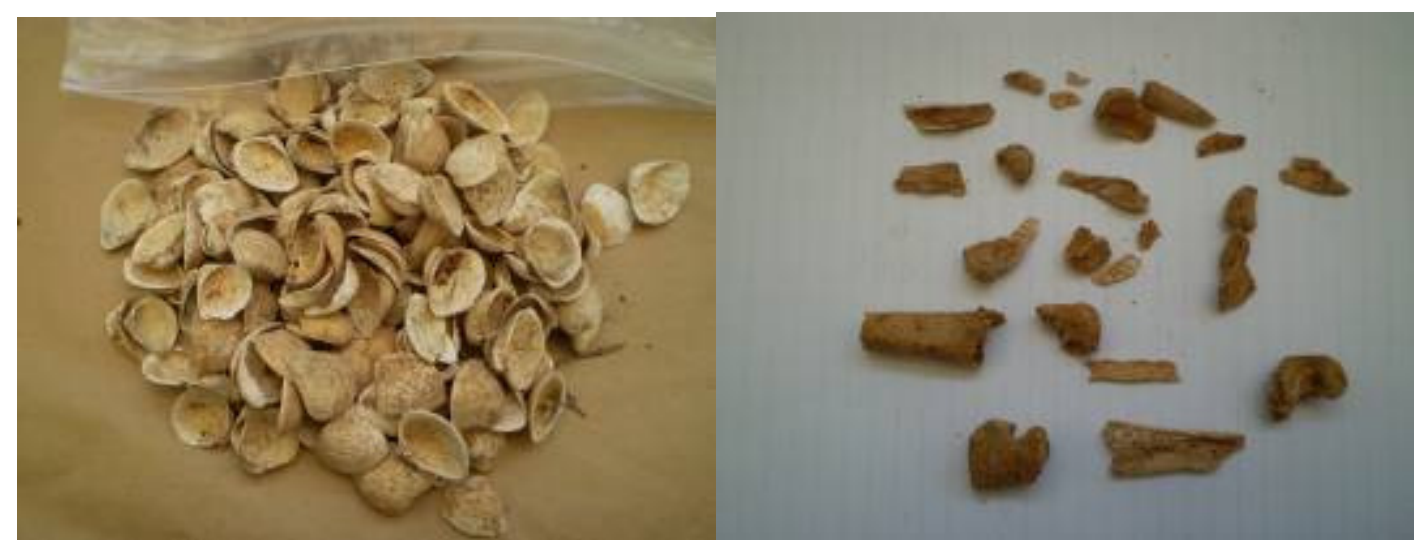

Figura 18: Fragmentos de bivalves, aparentemente todos da mesma espécie, e fragmentos de ossos de ave (?). Fotos: Charles Bonetti.

Figure 18: bivalve fragments, apparently all the same species, and bird bone fragments (?). Photos: Charles Bonetti. 


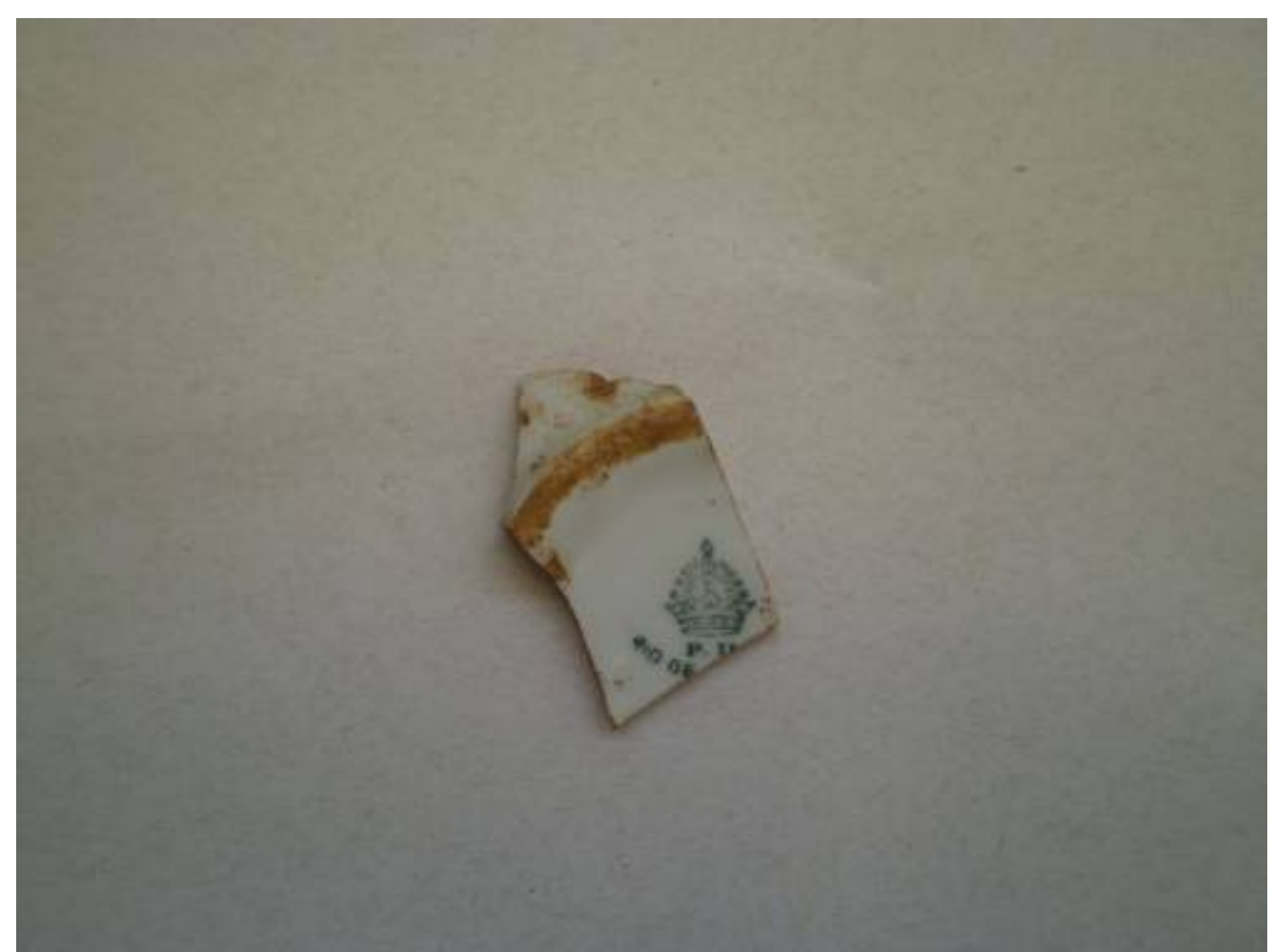

Figura 19: Detalhe do fragmento de louça ou porcelana com desenho encontrado durante a escavação, com as inscrições "PII" e "Rio de Janeiro". Foto: Charles Bonetti.

Figure 19: Dish fragment detail or porcelain with design found during the excavation, with the inscriptions "PII" and "Rio de Janeiro". Photo: Charles Bonetti.

\section{Considerações finais}

Os dados obtidos no diagnóstico prospectivo indicam a existência de um sítio arqueológico com diferentes ocupações, possivelmente de diferentes épocas, de povos ceramistas em função dos dois tipos distintos de fragmentos cerâmicos encontrados. Há também a possibilidade desse sítio ter sido um local de passagem, talvez um sítio histórico, em função da louça (?) ou porcelana (?) com desenhos, inclusive com as menções " $P$ Ir', "Rio de Janeiro" e o "Brasão do Império". Soma-se a essas ocupações, a existência de um depósito de carapaças de conchas, provavelmente de origem marinha, no interior de uma das quadras escavadas, o que o remete também a uma classificação inicial de sítio conchífero.

Apenas uma escavação sistemática poderá esclarecer a relação entre essas diversas ocupações, além de poder fornecer uma cronologia, pois nessa oportunidade não foram realizadas datações. O perímetro de interesse arqueológico, conforme apresentado na planta do terreno acima, (engloba dos pontos PB2 - PB5 até o muro que separa a Chácara Columbia da linha de alta tensão, ou seja, dos pontos PC2 ao PC6, dos pontos PD2 ao PD4 até o "linhão") no entanto, destaca-se que a feitura de trincheiras para além do perímetro arqueológico também deve ser realizada para uma melhor visualização da estratigrafia.

Os indícios materiais encontrados podem ajudar a corroborar algumas informações importantes dos cronistas dos séc. XVI e XVII, dentre as quais destacamos a de que os índios habitantes do planalto desciam a Serra do 
Mar para a coleta de moluscos, ostras, crustáceos e berbigões, movimento conhecido na época como prática de "mariscar", como nos atesta Frei Gaspar da Madre de Deus no século XVIII para a Província de São Paulo:

\begin{abstract}
Êste território, e tôda a Costa circunvizinha, assim para o Norte, como para o Sul, pertencia a várias Aldeias situadas no campo, sôbre as Serras: Ilhas de S.Vicente e Santo Amaro, e também a terra firme adjacente e suas praias, defendiam os índios, pela única conveniência de nelas pescarem e mariscarem. Eis aqui a razão por que Martim Afonso não viu aldeia alguma, depois passou a Enseada dos Maramomis. Índios particulares, em todo o tempo, e povos inteiros, em certos meses, vinham mariscar na costa: escolhiam entre os Mangais algum lugar enxuto, onde se arranchavam e dali saíam como enxames de abelhas a extrair do lodo os testáceos marítimos. É indizível a imensidade que colhiam de ostras, berbigões, amejoas, sururus de várias castas, e outros mariscos; mas a pesca principal era de ostras e berbigões, ou porque gostassem mais dêles, ou porque os encontrassem em maior cópia, e colhessem com facilidade. De tudo isto havia, e ainda hoje há, muita abundância nos mangais da Capitania de S.Paulo. Com os tais mariscos se sustentavam enquanto durava a pescaria, o resto secavam, e assim beneficiado conduziam para suas Aldeias, onde the servia de alimento por algum tempo. As conchas lançavam a uma parte do lugar onde estavam congregados, e com elas formaram montões tão grandes, que parecem outeiros a quem agora os vê soterrados (LIVRO I - FUNDAÇÃO DA CAPITANIA DE S. VICENTE POR MARTIM AFONSO DE SOUZA, SEU PRIMEIRO DONATÁRIO. MADRE DE DEUS, Fr. G., 1953, pp.44-45).
\end{abstract}

Cronistas mais antigos também registraram tal prática em seus escritos e em outras regiões do Brasil, como Gabriel Soares de Sousa para o sul, referindo-se aos Tapuyas:

\footnotetext{
Esta costa desde o rio dos Patos até a boca do rio da Prata é povoada de Tapuyas, gente doméstica e bem acondicionada, que não come carne humana nem faz mal à gente branca que os comunica, como são os moradores da capitania de São Vicente, que vão em caravelões resgatar por esta costa com este gentio alguns escravos, cera da terra, porcos, galinhas e outras coisas, com quem não tem nunca desavenças; e porque a terra é muito rasa e descoberta aos ventos, e não tem matos nem abrigadas, não vivem estes Tapuyas ao longo do mar e têm suas povoações afastadas para o sertão, ao abrigo da terra, e vêm pescar e mariscar pela costa. (Cap 72: Em que se conta como corre a costa do rio de São Pedro até o cabo de Santa Maria. SOUSA, G. S., 2010, p.117).
} 
O costume de mariscar parece ter sido bastante comum e uma constante para certas regiões, hábito notado até pelos naturalistas e viajantes do final do século XVIII e início do XIX, como Auguste de SaintHilaire que em 1816 descreve em sua obra "Viagem pela província de São Paulo" a mesma prática entre os guaianases:

Quando Martim Afonso aportou à llha de São Vicente, essa parte do Brasil pertencia aos pacíficos índios guaianases, que habitavam o planalto situado ao norte da cadeia marítima mas que, numa certa época do ano, costumavam descer até o litoral para procurar ostras e outros moluscos (Cap. I - Dados sumários sobre a Província de São Paulo História. SAINT-HILAIRE, A., 1976, p.18).

Em relatório entregue ao Instituto do Patrimônio Histórico e Artístico Nacional de São Paulo (IPHAN-SP), apesar da área de pesquisa encontrarse dentro de uma propriedade privada e devidamente murada, recomendamos o cercamento do perímetro de interesse arqueológico descrito e indicado em planta para sua maior proteção, além de seu imediato tombamento por se tratar de uma área de elevada relevância arqueológica, histórica e patrimonial.

No relatório também recomendamos, caso existisse interesse dos proprietários em liberar a área para uso privado, a realização de uma arqueologia de salvamento, bem como a realização posterior de uma intervenção museológica com o intuito de divulgar e preservar esse patrimônio.

Por ser o município de São Bernardo do Campo, notadamente o bairro de Rudge Ramos, carente de áreas verdes, a criação de um espaço museológico-arqueológico aberto à população, ou mesmo de um sítioescola, poderia ajudar a sanar essa lacuna, contribuindo para a oferta de um atrativo ecoturístico e um aumento da qualidade de vida na região, além de potencial para ajudar a aprofundar o conhecimento do processo histórico de ocupação da região.

Ressaltamos uma vez mais que esse trabalho apenas realizou 0 registro arqueológico de antigas ocupações no local e que apenas uma escavação sistemática pode revelar o processo de ocupação, a tipologia do material encontrado, a cronologia e a(s) cultura(s) que ocupou(aram) o lugar. Como dito anteriormente, todo o material arqueológico encontrado nas escavações foi encaminhado ao Conselho de Patrimônio do município (COMPAHC), cuja relação encontra-se em anexo nesse artigo.

\section{Referências bibliográficas}

AB'SABER, A. N. São Paulo: Ensaios e Entreveros. São Paulo: EDUSP, 2004.

AB'SABER, A. N. Geomorfologia do Sítio Urbano de São Paulo. São Paulo: Ateliê Editorial, 2007. 
ALDEA, C.; VALDOVINOS, C. Moluscos de Intermareal Rocoso Del centro-sur de Chile (36 - $\left.38^{\circ} \mathrm{S}\right)$ : Taxonomia y Clave de Identification. Unidad de Sistemas Acuáticos, Centro de Ciencias Ambientales EULA-Chile, Universidad de Concepción, Casilla 160-C, Concepción, Chile.

BASTOS, R.L.; TEIXEIRA, A. Normas e Gerenciamento do Patrimônio Arqueológico. São Paulo: 9 `SR/IPHAN, 2005.

COMPAHC. Inventário dos bens culturais. São Bernardo do Campo, s/d.

HOLANDA, S. B. Caminhos e Fronteiras. São Paulo: Companhia das Letras, 2008.

MADRE DE DEUS, F.G. Memórias para a História da Capitania de S. Vicente hoje chamada de S. Paulo. Com introdução de Afonso de E. Taunay. Biblioteca Histórica Paulista. São Paulo: Livraria Martins Francisco Editôra S.A., 1953.

PROUS, A. Arqueologia Brasileira. Brasília. Ed. UnB, 1992.

SANIT-HILAIRE, A., 1779-1853. Viagem à província de São Paulo. Tradução de Regina Regis Junqueira; apresentação de Mário Guimarães Ferri. Belo Horizonte, Ed. Itatiaia; São Paulo, Ed. Da Universidade de São Paulo, 1976.

SOUSA, G.S. (Década de 1540 - 1591). Tratado descritivo do Brasil em 1587. / Gabriel Soares de Sousa. Organização de Fernanda Trindade Luciani. - São Paulo: Hedra, 2010.

UNESCO - Organização das Nações Unidas para a Educação, a Ciência e a Cultura. Recomendação relativa à salvaguarda dos conjuntos históricos e sua função na vida contemporânea - 19a Sessão. 26 de novembro de 1976.

\section{Notas:}

${ }^{1}$ Av. Senador Vergueiro $n^{\circ} 3490$, esquina com Rua Sapucaí, no bairro de Rudge Ramos no município de São Bernardo do Campo, São Paulo.

${ }^{2}$ Srs. Sergio Roberto Ballotim, José Emilio Pessanha e Sidney Brochim na época da feitura dos trabalhos.

${ }^{3}$ Através da empresa Helbor - Empreendimentos Imobiliários.

${ }^{4}$ COMPAHC. Inventário dos bens culturais. São Bernardo do Campo, s/d.

${ }^{5}$ Idem. Dessa forma, a PEABIRU - TRABALHOS COMUNITÁRIOS E AMBIENTAIS foi contratada pelos empreendedores para a elaboração do estudo patrimonial da referida área, que por sua vez contatou o autor dessa nota prévia para a realização de um diagnóstico prospectivo arqueológico para a emissão do laudo solicitado pelo órgão municipal de patrimônio e entregue ao IPHAN - Instituto do Patrimônio Histórico e Artístico Nacional, $9^{\circ}$. Superintendência Regional - São Paulo. Processo IPHAN N 01506.002748/2008-84 publicado no Diário Oficial da União Seção 1, $\mathrm{N}^{\circ} 92$, 18 de maio de 2009 , produzido nos moldes do artigo $5^{\circ}$ da Portaria SPHAN $\mathrm{n}^{\circ} 007$ de 01 de dezembro de 1988. 
${ }^{6}$ Recomendação relativa à salvaguarda dos conjuntos históricos e sua função na vida contemporânea, 19a Sessão de 26 de novembro de 1976.

7 Ver Aziz Nacib Ab'Saber, São Paulo: Ensaios e Entreveros (2004) e Geomorfologia do Sítio Urbano de São Paulo (2007).

${ }^{8}$ (São Bernardo do Campo / COMPAHC. Inventário dos bens culturais).

${ }^{9}$ Sérgio Buarque de Holanda refere-se aos paulistas como uma sociedade talhada pelo caminho e pelo movimento, em oposição ao sedentarismo do nordeste durante o período colonial (Caminhos e Fronteiras, 1956).

10 Todo material arqueológico recolhido ficou sob a guarda e responsabilidade da Secretaria de Cultura de São Bernardo do Campo através do COMPAHC, órgão responsável pela gestão e gerenciamento do patrimônio cultural municipal, e disponível para pesquisas futuras.

Charles Bonetti: Museu de Arqueologia e Etnologia da USP; Universidade São Judas Tadeu, São Paulo, SP, Brasil.

E-mail: charlesbon@uol.com.br

Link para o currículo Lattes: http://lattes.cnpq.br/647931913454221

Data de submissão: 30 de outubro de 2014

Data de recebimento de correções: 24 de novembro de 2014

Data do aceite: 24 de novembro de 2014

Avaliado anonimamente 


\section{ANEXO}

\section{RELAÇÃO DE MATERIAL ARQUEOLÓGICO COLETADO ENTREGUE AO COMPACH DE DO MUNICÍPIO DE SÃO BERNARDO DO CAMPO.}

PC2 a 0,30m de profundidade:

1 frag. de louça (?) ou porcelana (?) branca de 2,0 (comprimento) $X$ 1,7 (largura) X 0,3cm (espessura);

1 frag. de vidro com 2,1 X $1,7 \times 0,3 \mathrm{~cm}$;

PC3 a $0,40 \mathrm{~m}$ de profundidade:

1 frag. de borda de cerâmica de $3,7 \times 5,1 \times 0,88 \mathrm{~cm}$.

1 frag. de borda de cerâmica de $3,7 \times 5,1 \times 0,88 \mathrm{~cm}$.

PC4 a $0,35 \mathrm{~m}$ de profundidade:

1 frag. de vidro de $3,36 \times 2,3 \times 0,5 \mathrm{~cm}$.

A $0,40 \mathrm{~m}$ de profundidade:

1 frag. cerâmico de $4,92 \times 2,88 \times 1,2 \mathrm{~cm}$;

1 frag. cerâmico de $2,35 \times 1,76 \times 0,93 \mathrm{~cm}$;

1 frag. cerâmico de $1,14 \times 0,7 \times 1,0 \mathrm{~cm}$;

PC5 a 0,20m de profundidade:

1 frag. de carvão;

3 frags. de vidro verde;

4 frags. de louça (prato?), sendo 2 cromados na cor azul;

1 frag. de louça (?) branca com desenho verde de $2,5 \times 2,5 \times 0,5 \mathrm{~cm}$.

A $0,5 \mathrm{~m}$ de profundidade:

1 frag. de carvão.

PD3 a 0,10m de profundidade:

1 frag. de porcelana (?) ou louça (?) de $3,5 \times 2,82 \times 0,34 \mathrm{~cm}$ com a incrição: "PONSTONE WAR...";

1 frag. de borda de porcelana (entulho ?) de 4,2 $\times 2,2 \times 1,45 \mathrm{~cm}$;

1 frag. de borda de porcelana (entulho ?) de $3,7 \times 1,4 \times 1,3 \mathrm{~cm}$;

1 frag. de borda de porcelana (?) ou louça (?) de pires (?) de 3,4 X 2,2 $X 0,25 \mathrm{~cm}$ com as inscrições ao fundo de "PII" e "RIO DE ..." e o desenho do brasão do Império (?);

1 frag. de borda de louça (?) ou porcelana (?) branca sem inscrições de $3,0 \times 2,7 \times 1,05 \mathrm{~cm}$;

A $0,40 \mathrm{~m}$ de profundidade:

1 pacote de conchas de aproximadamente 400 gramas;

23 frags. ósseos;

PD4 a $20 \mathrm{~cm}$ de profundidade:

1 frag. de xícara;

1 frag. de prato de porcelana (?) ou louça (?); verde

1 frag. de porcelana (?) ou louça (?) branca com desenho na cor

PD7 a $20 \mathrm{~cm}$ de profundidade:

2 frags. de louça sanitária (?) marrom;

1 frag. de piso preto (lajota?);

1 frag. de seixo sem sinal de uso;

2 frags. de louça (?).

TOTAL: 55 fragmentos coletados, mais 1 pacote de conchas. 